\title{
The Dutch Famine, 1944-1945, and the Reproductive Process. I. Effects on Six Indices at Birth
}

\author{
ZENA STEIN AND MERVYN SUSSER \\ New York State Department of Mental Hygiene and School of Public Health, Columbia University, \\ New York, New York, USA
}

\section{Extract}

Prenatal exposure to the Dutch famine of 1944-1945 reduced postpartum maternal weight, birth weight, placental weight, length at birth, and head circumference at birth. These conclusions are based on maternities occurring in the famine area and exposed to famine during some part of gestation as compared both with maternities in nonfamine areas, and with maternities before and after the famine. Third trimester exposure accounted for the whole of the famine effects. Length of gestation was not affected by third trimester exposure, and did not mediate the effects on infant dimensions at birth. Effects were apparent only below a threshold value of official food rations of 1,500 cal daily average during the third trimester. (Calorie value for official food rations can be assumed to be lower than actual food intake.) Maternal weight declined $4.3 \%$ during the famine and rose $10.5 \%$ after the famine. Birth weight declined $9 \%$ during the famine, and rose $9 \%$ after the famine. Placental weight declined $15 \%$ during the famine, and rose $14 \%$ after the famine. Length at birth declined $2.5 \%$ during the famine, and rose $1.5 \%$ after the famine. Head circumference declined $2.7 \%$ during the famine, and rose $2.4 \%$ afterward.

\section{Speculation}

The Dutch famine experience is analogous to animal experiments in which severe early nutritional deprivation slows fetal growth, including the head, and perhaps causes brain cell depletion.

The relation of fetal growth to maternal nutrition has interest for the understanding of the reproductive process. This relation has even greater interest as a link in a postulated causal chain that runs from maternal nutrition through fetal growth and the capacity for survival, growth, and development $(4,27)$. Epidemiologic observations are summarized by Hytten and Leitch (16). Suspicions that dated from the effects of the British blockade of Germany in World War I were confirmed in World War II. Thus the reported effects on birth weight of the Dutch famine of 1944-1945 and of the siege of Leningrad of 1941-1943 provoked the present study of the Dutch famine $(1,25)$. The circumstances of the famine have been described elsewhere $(5,28,29)$. A commonly accepted date of onset is mid-October 1944; its end was sudden, when the Allied armies liberated Holland on May 7, 1945.

We chose to confirm and extend the earlier reports of the effects of the Dutch famine on birth weight $(24,25,31)$ in three respects. First, we sought to test the finding of fetal growth retardation by replicating it in a number of faminestricken cities. Second, we sought to complement the rigor of the "before-and-after" time control used in previous studies with cross-sectional geographic controls from areas unaffected by the famine. Third, we sought to analyze available dimensions of fetal growth, and so to achieve a fuller perspective of the nature of the growth process. We examined six separate indices of birth process: birth weight, placental weight, infant length at birth, head size at birth, duration of gestation, and maternal weight.

\section{DATA SOURCES, DESIGN, AND METHODS}

Records of maternities and of the characteristics of infants at birth were obtained from teaching hospitals in Amsterdam, Leiden, and Rotterdam in the famine area, and in Groningen in the North and Heerlen in the South, both areas unaffected by famine although on low rations.

These data suffer from a problem of unrepresentativeness; at that time, more than half of the births took place outside the hospitals. The bias is to some extent controlled by analyses within each hospital population over the relevant time period. As far as we could discover, none of the hospitals changed their admission procedures during the time of the study and there is no reason to suspect a change in the nature of the populations they served during the study period. The social attributes of the patients admitted are reported to be auite different in each hospital in the famine area; the consistency of results across these hospitals therefore can provide a further test for the presence of bias due to social selection.

The research design was of the historical cohort type. Entry of the cohorts to the study was at birth over the 20-month period, August 1944 through March 1946. We used two forms of comparison: one compared exposed cohorts with cohorts whose gestation either preceded or followed the famine; the other compared exposed cohorts with those born at the same time, but in unaffected areas. Thus, in this report, prenatal exposure to famine is treated as a dichotomous variable. The use of the official weekly food ration as a quantified independent variable is reported in detail elsewhere (29). Table 1 shows the official ration through the period of the study in terms of calories, proteins, carbohydrates, and fats.

The dates of conception are inferred from dates of birth. The average error in these estimates is bound to be small because the average reduction in the duration of gestation during the famine was about 4 days. Monthly birth cohorts 
Table 1. Rations of calories, protein, fats, and carbohydrates in 3-month averages for the period June 1944 to August 1946 inclusive 1

\begin{tabular}{|c|c|c|c|c|c|c|c|c|}
\hline Area & $\begin{array}{c}\text { June-Aug. } \\
1944\end{array}$ & $\begin{array}{c}\text { Sept.-Nov. } \\
1944\end{array}$ & $\begin{array}{c}\text { Dec. }- \text { Feb. } \\
1944-45\end{array}$ & $\begin{array}{c}\text { Mar.-May } \\
1945\end{array}$ & $\begin{array}{c}\text { June-Aug. } \\
1945\end{array}$ & $\begin{array}{c}\text { Sept.-Nov. } \\
1945\end{array}$ & $\begin{array}{c}\text { Dec. }- \text { Feb. } \\
1945-46\end{array}$ & $\begin{array}{c}\text { Mar.-Apr. } \\
1946\end{array}$ \\
\hline \multicolumn{9}{|l|}{ Calories } \\
\hline West & 1,512 & 1,414 & 740 & 670 & 1,757 & 2,083 & 2,270 & 3,200 \\
\hline North & 1,512 & 1,450 & 1,345 & 1,392 & 1,755 & 2,083 & 2,270 & 3,200 \\
\hline South & 1,512 & 1,403 & 1,375 & 1,692 & 1,864 & 2,083 & 2,270 & 3,200 \\
\hline \multicolumn{9}{|l|}{ Proteins, g } \\
\hline West & 42 & 40 & 21 & 14 & 55 & 61 & 65 & 94 \\
\hline North & 42 & 42 & 38 & 43 & 53 & 61 & 65 & 94 \\
\hline South & 42 & 42 & 44 & 50 & 58 & 61 & 65 & 94 \\
\hline \multicolumn{9}{|l|}{ Fats, g } \\
\hline West & 32 & 25 & 15 & 12 & 54 & 50 & 51 & 96 \\
\hline North & 32 & 26 & 23 & 26 & 39 & 50 & 51 & 96 \\
\hline South & 32 & 25 & 21 & 28 & 38 & 50 & 51 & 96 \\
\hline \multicolumn{9}{|c|}{ Carbohydrates, g } \\
\hline West & 275 & 253 & 127 & 119 & 268 & 333 & 362 & 465 \\
\hline North & 275 & 259 & 237 & 237 & 283 & 333 & 362 & 465 \\
\hline South & 275 & 251 & 245 & 300 & 317 & 333 & 362 & 465 \\
\hline
\end{tabular}

${ }^{1}$ Data from Burger et al. (5),

were grouped into seven cohorts of unequal size, by the criterion of stage of gestation in relation to famine exposure. In Figure 1 each successive monthly cohort is represented by a bar beginning at estimated time of conception and ending at birth, and grouped into the larger cohorts defined as follows: cohort A (births from August through October, 1944), conceived and born before the famine; $B 1$ (births from November, 1944 through January, 1945) and $B 2$ (births from February through April, 1945), conceived before the famine and born during the tamine ( $B \perp$ was exposed to famine for the third trimester of gestation only, and $B 2$ was exposed for the second trimester as well as the third); $C$ (births from May through June, 1945), conceived before and born after the famine ( $C$ was exposed to famine during the middle 6 months of gestation); $D 1$ (births from July through September, 1945) and D2 (births from October, 1945 through January, 1946), conceived during the famine and born after it (D1 was exposed to famine during the first and second trimester of gestation, $D 2$ only during the first); $E$ (births from February through March, 1946), conceived and born after the famine and never exposed.

The mean values of the outcome variables are given for birth cohorts in famine-stricken and in control areas in graphic presentations. The analysis includes data from all five hospitals whose records were extracted; omissions are noted as they aris. First we deal with the group of four variables (birth weight, placental weight, infant length, head size) that derive from fetal dimensions and measure fetal growth; they are treated in order of size of effects. Then we deal with two variables, duration of gestation and maternal weight, that reflect maternal change as much as or more than fetal change (38).

\section{RESULTS}

\section{BIRTH WEIGHT (FIG. 2)}

In before-and-after studies of the Dutch famine, Sindram (24), Smith (25), and Stroink (31) all found a fall in birth weight coincident with the famine (17). As Smith suggested and we have confirmed, the fall was related to mothers' exposure to famine during the third trimester. We could perceive in Smith's data no added effect from exposure during the first and second trimester (4). Smith also found an excess of "premature" infants of very low birth weight among births conceived during the famine and exposed to it early in

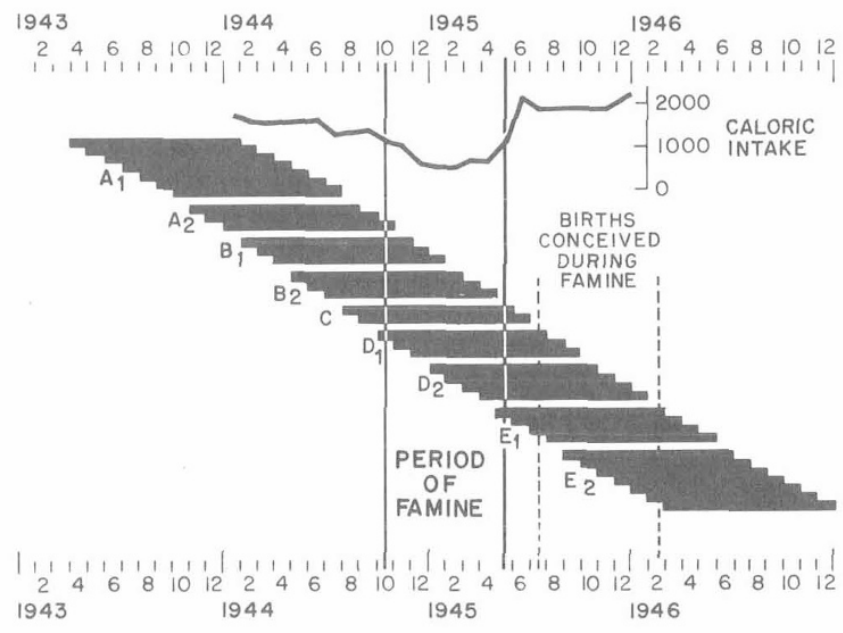

Fig. 1. Design of study. Cohorts by month of conception and month of birth, in The Netherlands, 1943-1946, related to calories in the rations of famine cities. Solid vertical lines bracket the period of famine, and broken vertical lines bracket the period of births conceived during famine. For groupings of the larger cohorts, see Data Sources, Design, and Methods.

gestation. This result did not reach conventional levels of statistical significance.

The standard deviations and the means in each hospital suggest acceptable levels of reliability in measurement (Table 2). Our data show a distinct fall in mean birth weight related to exposure to famine. In the two nonfamine areas at the same period, the fall in mean birth weight was moderate in the North and slight in the South. The decline in birth weight in the nonfamine areas affected monthly birth cohorts differently from those in the famine area, but also to some extent followed a decline in rations.

Visible effects of famine on birth weight are confined to exposure during the third trimester at a level of average daily official rations less than $1,500 \mathrm{Cal}$, which coincides with the general consensus about the point at which famine had its onset (39). In the famine area the most affected cohorts are $B 1, B 2$, and $C$. Exposure solely during the third trimester (cohort B1) coincided with a fall in birth weight. Exposure solely during the first trimester (cohort D2), or during both 


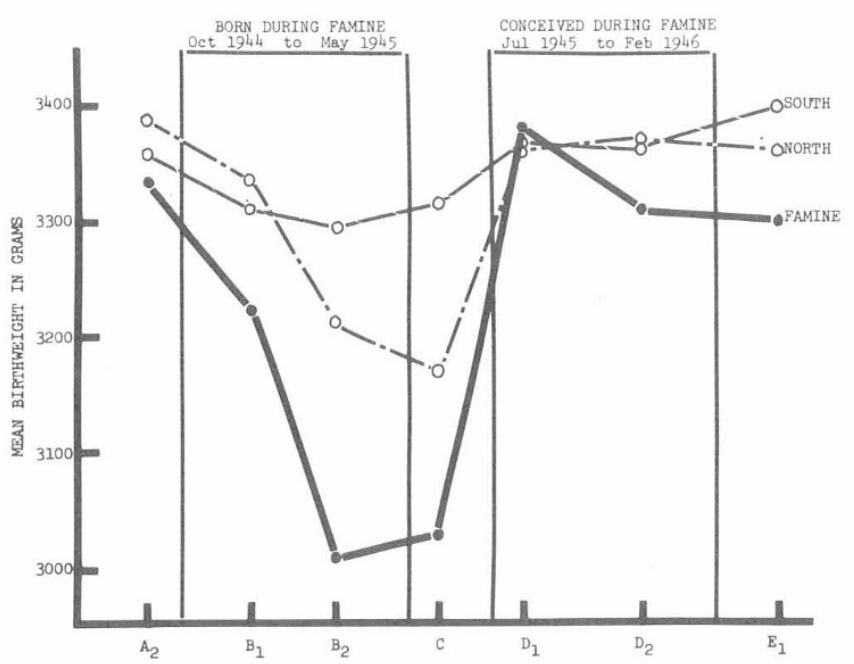

Fig. 2. Birth weight by time and place. Mean birth weight in grams for consecutive births in maternity hospitals for seven birth cohorts: famine, North control, and South control areas compared for the period August 1944 to March 1946 inclusive.

Table 2. Birth weights

\begin{tabular}{lrrr}
\hline & Mean, g & SD & \multicolumn{1}{c}{$\mathrm{n}$} \\
\hline Amsterdam & 3,211 & 665 & 1,148 \\
Leiden & 3,331 & 607 & 457 \\
Rotterdam & 3,245 & 654 & 806 \\
Groningen & 3,311 & 659 & 1,290 \\
Heerlen & 3,345 & 551 & 1,149 \\
\hline
\end{tabular}

first and second trimester (cohort D1), produced no detectable effect on birth weight. The greater apparent effect of exposure during both second and third trimester (cohort B2), therefore, can best be attributed to the greater severity of famine during the third trimester of the affected cohort. The low mean birth weight of cohort $C$ indicates an effect of early third trimester famine exposure not reversed by a period of access to normal nutrition in the very last weeks of gestation.

Although there was no reduction in the mean birth weight of the D2 cohort, the cohort has a wider standard deviation than other cohorts. This was caused by an excess of infants of birth weight under $2,000 \mathrm{~g} ; 27$ were expected, and 37 were observed. There is reason to consider the excess biologically significant because of its coincidence with other manifestations in the D2 cohort (29), but it was not statistically significant.

We conclude that a predominant effect of food deprivation on birth weight was caused by third trimester exposure to famine below a threshold value of food intake. In the famine area, mean birth weight, $3,338 \mathrm{~g}$ in the $A$ cohort born before the famine, declined by $9 \%$ in the $B 2$ cohort born during the famine, and rose by $8.9 \%$ to $3,308 \mathrm{~g}$ in the $E$ cohort born after the famine.

\section{PLACENTAL WEIGHT}

Placental weight is correlated with birth weight $(2,9,26$, 34). In animals, a loss of placental weight follows nutritional deprivation. We know of no studies among humans that relate the mother's nutrient intake to placental weight at birth. Mothers from populations that suffer chronic malnutrition, however, tend to have babies of low birth weight and also to deliver lighter placentae. Biochemical changes are associated with these weight changes $(18,19,35-37)$.

The data on placental weight shown in Figure 3 do not include births in Amsterdam and Leiden. The standard deviations and the means in each hospital suggest substantial variation in reliability of measurement (Table 3 ). We have no information on the way in which the placentae were weighed.

In the famine-stricken city of Rotterdam, mean placental weight declined in a manner concomitant with changes in food rations and with changes in birth weight; the $B 2$ and $C$ cohorts were chiefly affected. In the cities of the control areas, the fluctuations in placental weight were also compatible with changes in rations, although less so. In the control area of Heerlen in the South, the $B 2$ cohort was most affected; in the control area of Groningen in the North the $C$ cohort was most affected. The curious fall in mean placental weight in Groningen to the low value of the $C$ cohort, however, cannot be explained in terms of the official caloric ration.

The main changes in placental weight, like birth weight, relate to exposure to low food rations below a threshold level of $1,500 \mathrm{Cal}$ in the third trimester, despite the fact that in normal circumstances placental growth probably reaches a maximum somewhat earlier in pregnancy than does birth weight $(12,34)$. The inferences from which this conclusion derives are the same as for birth weight. In Rotterdam, the mean placental weight, $601 \mathrm{~g}$ in the $A$ cohort born before the famine, declined by $15 \%$ to $511 \mathrm{~g}$ in the $B 2$ cohort born during the famine, and on recovery rose by $14 \%$ to $592 \mathrm{~g}$ in the $E$ cohort conceived after the famine.

\section{INFANT LENGTH AT BIRTH}

C. A. Smith noted changes in infant length at birth during the Dutch famine, although they were not statistically significant; the reduction was less marked and consistent than changes in birth weight (25). In the famine of the 21 -month Leningrad siege in World War II, Antonov (1) also found a

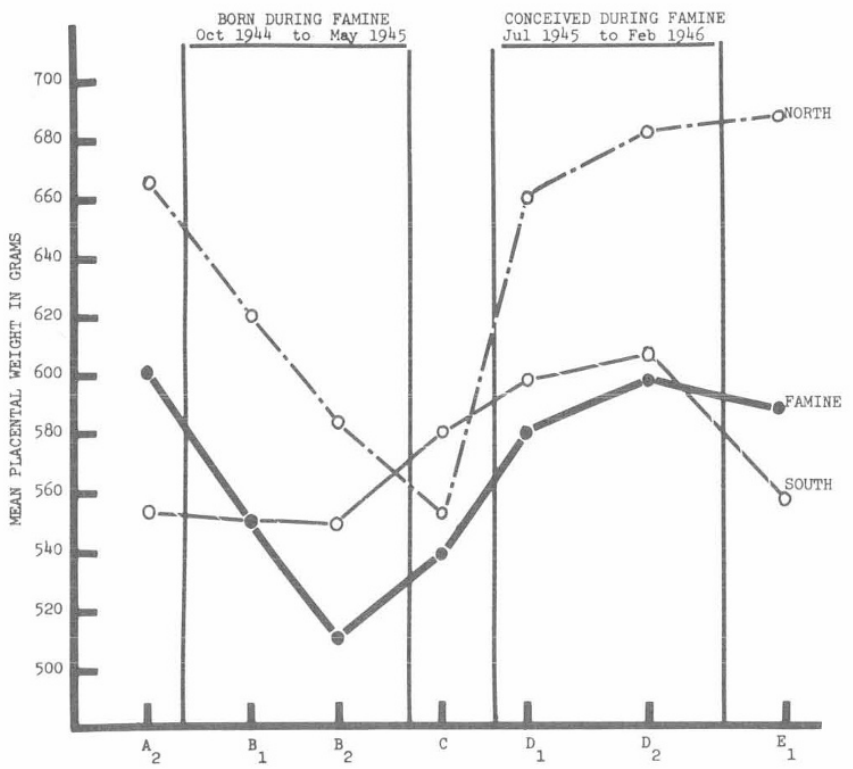

Fig. 3. Placental weight by time and place. Mean placental weight in grams for consecutive births in maternity hospitals for seven birth cohorts: famine, North control, and South control areas compared for the period August 1944 to March 1946 inclusive.

Table 3. Placental weight

\begin{tabular}{lccr}
\hline & Mean, g & SD & \multicolumn{1}{c}{$\mathrm{n}$} \\
\hline Rotterdam & 573 & 130 & 775 \\
Groningen & 641 & 147 & 1,236 \\
Heerlen & 575 & 160 & 1,097 \\
\hline
\end{tabular}


decrease in length among infants at birth. Shortness is associated with the more severe forms of fetal growth retardation (13), but the reports of Antonov and Smith provide the only direct evidence in humans of a nutritional effect on growth in fetal length.

The findings for infant length at birth are shown in Fig. 4. The reliability of measurement seems adequate (Table 4).

Infant length varied among the seven birth cohorts in a fashion similar to but less marked than birth weight and placental weight. A famine effect can be localized to exposure during the third trimester of pregnancy. There was no detectable effect of prenatal nutrition on length in nonfamine conditions, that is, above a threshold of about $1,500 \mathrm{Cal}$ average daily official ration. In the famine area the $B 1$ and $B 2$ cohorts, who suffered chiefly third trimester exposure, showed a relatively steep decline in length at birth of $2.5 \%$ from the $A$ cohort born before the famine. This low level continued through the $C$ cohort, as it did for other fetal dimensions. In the $E$ cohort born after the famine there was a rise of $1.5 \%$ from the level of the $B 2$ cohort. In the northern control area, there was a sharp decline in infant length in the $D 2$ cohort. We have no explanation for this effect in terms of food rations.

\section{HEAD SIZE AT BIRTH}

Head size has been shown to be smaller in malnourished children than in comparison groups $(7,21,30)$. In such children small head size occurs conjointly with other small body measurements, particularly height and weight. Small head size also seems to accompany retarded fetal growth (3, $13,14,22,23)$. Conversely, an increased rate of growth in head size in premature infants after birth has been attributed

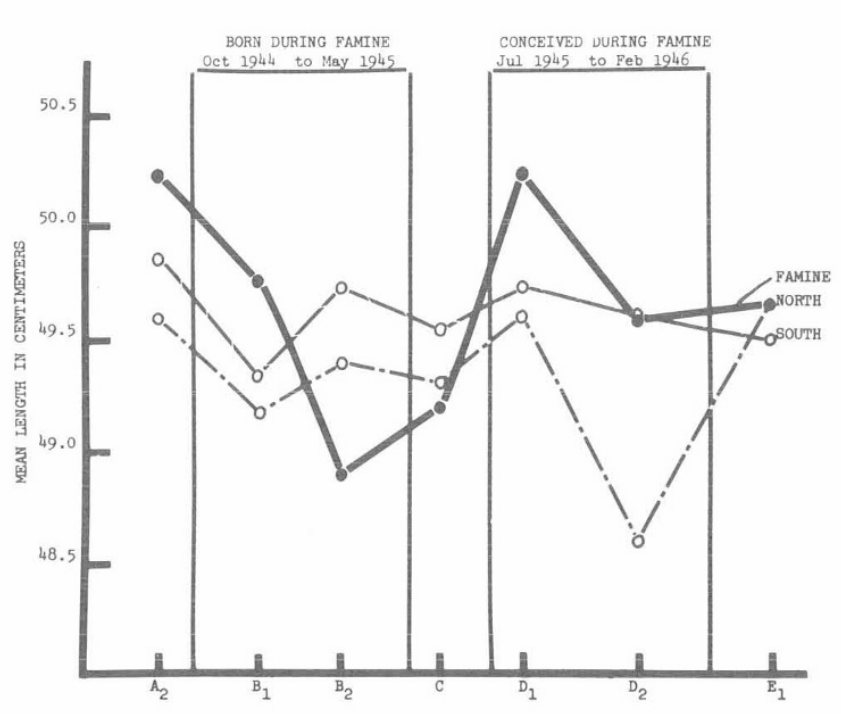

Fig. 4. Infant length by time and place. Mean infant length at birth in centimeters for consecutive births in maternity hospitals for seven birth cohorts: famine, North control, and South control areas compared for the period August 1944 to March 1946 inclusive.

Table 4. Infant length at birth

\begin{tabular}{lccc}
\hline & Mean, cm & SD & $\mathrm{n}$ \\
\cline { 3 - 4 } Amsterdam & 49.6 & 4.1 & 973 \\
Leiden & 50.0 & 3.9 & 457 \\
Rotterdam & 49.6 & 3.6 & 794 \\
Groningen & 49.3 & 3.5 & 1,272 \\
Heerlen & 49.6 & 2.8 & 1,129 \\
\hline
\end{tabular}

to improved nutrition brought about by changed hospital feeding practices. In premature infants born at the Hammersmith Hospital in London in 1965 through 1968, head size increased more rapidly than in those born 4 years earlier (8).

In presenting the Dutch data, we have chosen, from the five or six indices of head size recorded in each hospital series included in our analysis, to use "median head circumference." This measurement is the one most commonly reported in the literature. In our data, it is highly correlated with most of the other head measures $(r=0.7-0.9)$ and seemed to be one of the most sensitive to prenatal nutritional deprivation.

The data on head size are shown only for Rotterdam in the famine area, for Groningen in the North, and for Heerlen in the South (Fig. 5). In Rotterdam and Groningen data were available over a period of 20 months; in Heerlen the records were incomplete for the last 4 months. Agreement between hospitals is far from good (Table 5). The disparity between Groningen in the North and other areas is most likely a measurement problem, since among measures of fetal growth, the low mean value in Groningen is unique to this measure alone. Agreement between Heerlen in the South and Rotterdam in the famine area is better, despite the missing data for 4 months of the observation period.

In the famine area, the decline in head circumference among births during the famine period ( $B 1, B 2$ and $C$ cohorts) again suggests that prenatal exposure to famine in the third trimester of gestation affected this dimension of fetal growth. There was a maximum decline in level of the $B 2$ cohort of $2.7 \%$ from the $A$ cohort born before the famine. In the $E$ cohort born after the famine, there was a rise of $2.4 \%$ from the level of the $B 2$ cohort. The pattern in the famine area is fairly distinct from that in the South for the period in which data were available. For the period covered by the cohorts $B 2$ through E1, the

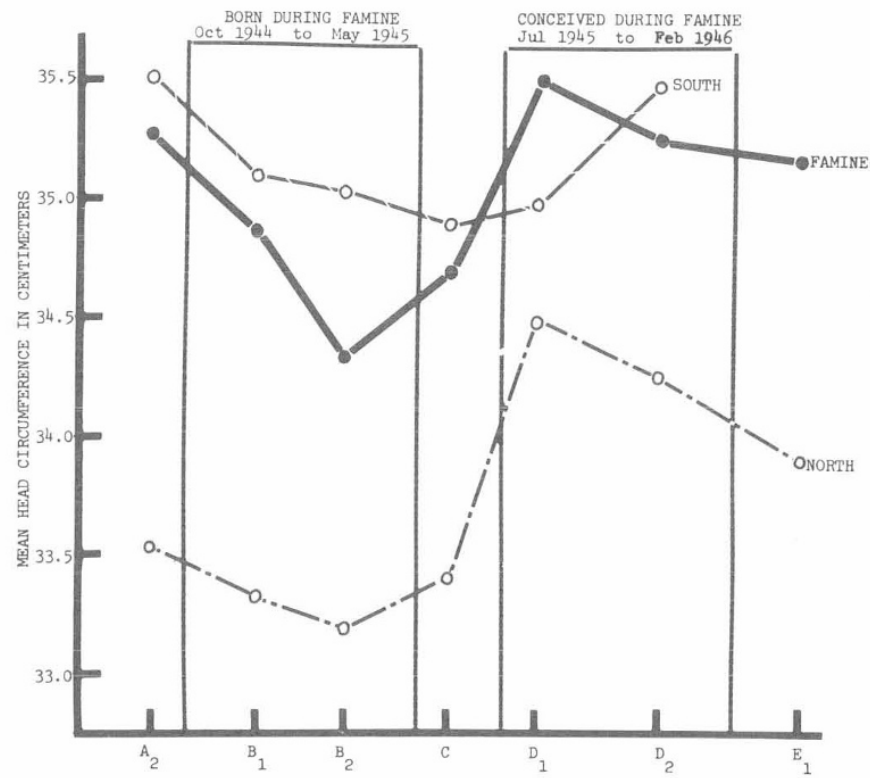

Fig. 5. Head circumference by time and place. Mean head circumference in centimeters for consecutive births in maternity hospitals for seven birth cohorts: famine, North control, and South control areas compared for the period August 1944 to March 1946 inclusive.

Table 5. Head size at birth

\begin{tabular}{lccr}
\hline & Mean, cm & SD & \multicolumn{1}{c}{$\mathrm{n}$} \\
\hline Rotterdam & 34.9 & 2.1 & 644 \\
Groningen & 33.7 & 1.5 & 1,179 \\
Heerlen & 35.1 & 1.7 & 760 \\
\hline
\end{tabular}


pattern in the famine area resembles that in the North. Among the the crucial cohorts that exhibit a famine effect however, the northern area does not show the sharp reduction in head circumference seen in the famine area.

\section{DURATION OF GESTATION}

The reported variation in average duration of gestation between human groups has been relatively small, for instance between social classes or ethnic groups $(6,15)$. Sirıdram (24) reported a mean reduction in length of gestation during the Dutch famine of 4 days, about $1 \%$. We have found no other reports of a direct effect of nutrition on length of gestation.

Our data were taken from hospitals in Amsterdam and Rotterdam in the famine area, Groningen in the North, and Heerlen in the South. Reliability of measurement seemed adequate (Table 6).

The shortened period of gestation in the $B 2$ cohort is consistent with an effect of third trimester famine exposure. The decrease from the $A$ cohort born before the famine, was 0.3 weeks, or $0.8 \%$, and the increase in the $E$ cohort born after the famine was 0.5 weeks, or $1 \%$ (Fig. 6).

Changes in length of gestation cannot be attributed to prenatal famine exposure with much conviction, because of inconsistencies in the common variation of the two study variables in the famine area. It is true that during the period of famine the pattern of changes in length of gestation at birth is similar to that of the outcome variables analyzed previously, and consistent with an effect of famine exposure during the third trimester of pregnancy. Also, in the $D 2$ cohort, exposed to famine only in the first trimester, there was an even more striking contraction of the average period of gestation. Famine exposure alone cannot explain this effect, however, since the

Table 6. Duration of gestation

\begin{tabular}{lccr}
\hline & Mean,wks & SD & \multicolumn{1}{c}{$\mathrm{n}$} \\
\hline Amsterdam & 39.4 & 2.3 & 1,144 \\
Rotterdam & 39.4 & 2.9 & 791 \\
Groningen & 39.5 & 2.4 & 1,021 \\
Heerlen & 39.5 & 2.5 & 1,085 \\
\hline
\end{tabular}

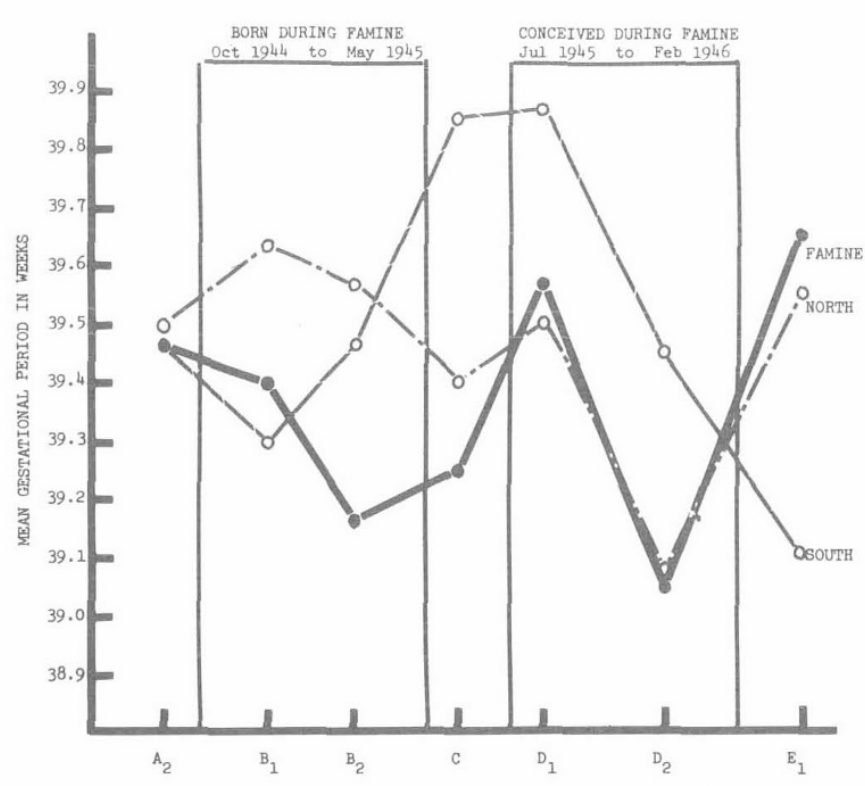

Fig. 6. Weeks of gestation by time and place. Mean weeks of gestation for consecutive births in maternity hospitals for seven birth cohorts: famine, North control, and South control areas compared for the period August 1944 to April 1946 inclusive.
D2 cohort in the northern control city of Groningen experienced as great a contraction. Moreover, the $D 1$ cohort was also exposured to famine at conception and early in pregnancy, and duration of gestation was not shortened. In the southern control city of Heerlen, length of gestation fluctuated widely without evident relation to food rations.

\section{MATERNAL WEIGHT (FIG. 7.)}

Estimated caloric intake has been found to correlate with maternal weight during pregnancy in a study in Aberdeen, Scotland (32). The relation was demonstrated in the course of an attempt to establish the connection between nutrition and birth weight. In that observational study the direction of the relation between nutrition and maternal weight could not be determined with certainty, for both the index of nutrition and the index of maternal weight were based on observations made at one point in pregnancy (mostly in the 7 th month). The partial correlation between caloric intake and birth weight disappeared when maternal weight was introduced into the analysis, and the investigator inferred that maternal weight must be the antecedent variable and common cause of both caloric intake and birth weight. Maternal height appeared to be the determinant of this association, for calorie intake increased with height and was similar for overweight and underweight women of the same height (33).

With regard to maternal weight, if not stature, however, another interpretation is possible, namely that caloric intake is the antecedent variable and maternal weight the intervening variable. All the data required to test these interpretations are not available, as they involve both height and weight during pregnancy. One point of interest in the Dutch data is that the direction of nutritional effects on maternal weight during the famine can be inferred with a high degree of certainty. A second point of interest is that maternal weight may also provide a criterion by which to judge the severity of the famine at different periods.

Our raw data for maternal weight are more limited than for other outcomes; they are available only for hospital births in the city of Rotterdam. With this variable, the problem of the time of measurement may be relevant to interpretation of effects at different stages of pregnancy. A single measurement was made just before discharge home, 9 or 10 days after delivery. About earlier stages of pregnancy, we can only say that any effects of food intake that may exist were overshadowed or reversed by the third trimester experience. The reliability of the measurements is difficult to estimate since our data were drawn from a single hospital, and we know of no other published series of mothers weighed at this same stage in the puerperium.

At the onset of the famine, wartime maternal weights were low in comparison with the immediate postwar norm. In this respect the variable differed from the other indices of the reproductive process. A sharp decline from this relatively low level of postpartum maternal weight quickly followed the reduction in food rations. The average decline from the prefamine level in the most affected cohort (B2) was $2.6 \mathrm{~kg}$ or $4.3 \%$ and the rise with recovery was $5.9 \mathrm{~kg}$, or $10.5 \%$. Both the rise and the fall of the curves for postpartum maternal weight were closely related to that of caloric rations towards the end of pregnancy. Thus, mothers of the $C$ cohort, who had an average of only 3 weeks to enjoy the more favorable conditions after liberation, had begun to recover.

\section{SUMMARY AND CONCLUSION}

During the Dutch hunger winter of 1944-1945 famine retarded fetal growth during late gestation. Food intake measured by official rations in the third trimester surely affected three of six indices of the reproductive process, namely birth weight, placental weight, and maternal weight at 


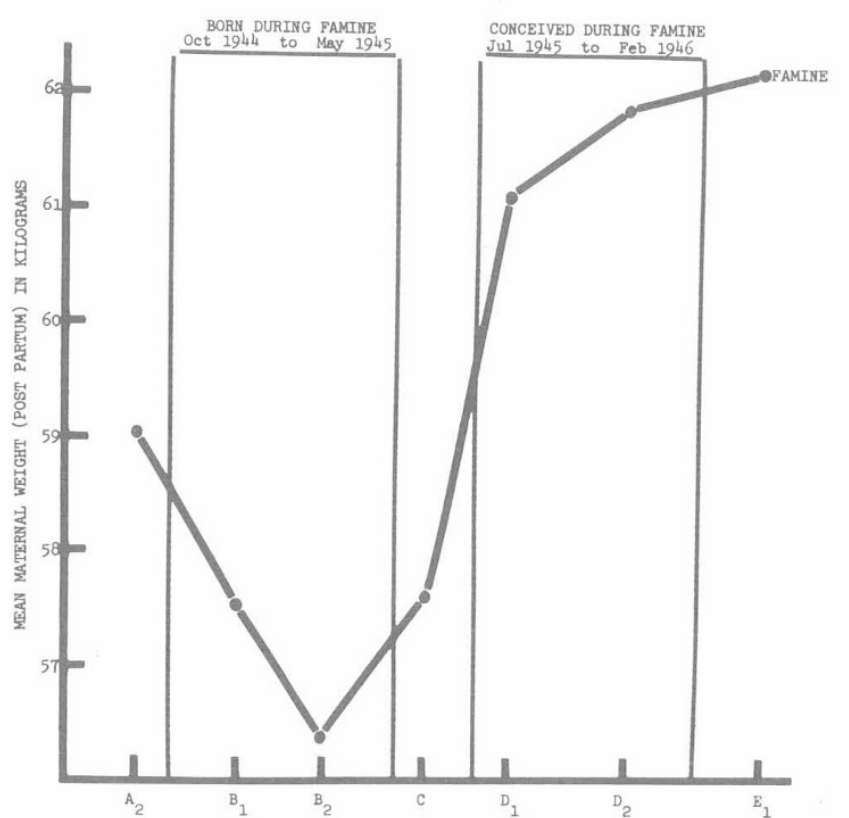

Fig. 7. Maternal weight by time and place. Mean maternal weight in kilograms for consecutive births in maternity hospitals for seven birth cohorts: famine, North control, and South control areas compared for the period August 1944 to April 1946 inclusive.

the end of pregnancy. Food intake affected infant length at birth to a smaller degree. It also affected head circumference the effect is less clear in certain of the analyses because in some hospitals the measure was unreliable. Although duration of gestation may have been affected, changes were small and difficult to interpret.

First trimester effects were equivocal. A first trimester effect on length of gestation was present, but was common to the famine and control areas. Moreover, a proportion of infants exposed to famine early in gestation were of very low birth weight; they had shortened periods of gestation and were born prematurely.

All the unequivocal effects of low food intake in slowing fetal growth could be localized to the third trimester of gestation. Among third trimester famine effects, only that on maternal weight was linear. All of the unequivocal third trimester effects on fetal growth were nonlinear; they occurred only below an empirical threshold of the average daily official ration during the third trimester of gestation of $1,500 \mathrm{Cal}$ or less.

In the end result, our data show that infants exposed to famine late in gestation were lighter than pre- or postfamine norms; to a lesser degree they were also shorter and had smaller heads. The smallness of these infants at birth was not mediated through shortened gestation, and can be attributed to a slowed rate of fetal growth (40). Unknown differences in the reliability with which each index was measured could have contributed to differences in their capacity to reflect effects of famine exposure. We have no way of estimating this contribution.

\section{REFERENCES AND NOTES}

1. Antonov, A. N.: J. Pediat., 30: 250 (1947).

2. Armitage, P., Boyd, J. D., Hamilton, W. J., and Row, B. C.: Hum. Biol., 39: 430 (1967).

3. Baum, J. D., and Searls, D.: Develop. Med. Child. Neurol., 13: 576 (1970).

4. Bergner, L., and Susser, M. W.: Pediatrics,.46: 946 (1970).

5. Burger, G. C. E., Drummond, J. C., and Sandstead, H. R. (eds.): Malnutrition and Starvation in Western Netherlands September 1944-July 1945 (General State Printing Office, The Hague, 1948).
6. Butler, N. R., and Bonham, D. G.: Perinatal Mortality: The First Report of the 1958 British Perinatal Mortality. Survey under the Auspices of the National Birthday Trust Fund (E. and S. Livingstone, Edinburgh, 1963).

7. Chase, H. P., and Martin, H. P.: New Engl. J. Med., 282: 933 (1970).

8. Davies, P. A., and Davies, J. P.: Lancet, ii: 1216 (1970).

9. Gerlach, H.: Thesis, University of Halle (1962). Cited by Armitage P., Boyd, J. D., Hamilton, W. J., and Row, B. C., Hum. Biol., 39: 430 (1967).

10. Gibson, J. R., and McKeown, T.: Brit. J. Soc. Med, 4: 221 (1950).

11. Gibson, J. R., and McKeown, T.: Brit. J. Soc. Med., 5: 177 (1951).

12. Gruenwald, P.: Biol. Neonatorum, 5: 215 (1963).

13. Gruenwald, P.: Amer. J. Obstet. Gynecol., 94: 1112 (1966).

14. Gruenwald, P., and Minh, H. N.: Amer. I. Obstet. Gynecol., 82: 312 (1961).

15. Henderson, M.: Arch. Environ. H1th. 14: 904 (1967)

16. Hytten, F, E., and Leitch, I.: The Physiology of Human Pregnancy (Blackwell Scientific Publications, Oxford, 1971).

17. Kloosterman, G. J.: Ned. T. Verlosk. 66: 361 (1966).

18. Laga, E. M., Driscoll, S. G., and Munro, H. N.: Pediatrics, 50: 24 (1972).

19. Laga, E. M., Driscoll, S. G., and Munro, H. N.: Pediatrics, 50: (1972).

20. McKeown, T., and Gibson, J. R.: Brit. J. Soc. Med, 5: 98 (1951).

21. Monckeberg, F.: In: N. E. Scrimshaw and J. E. Gordon: Malnutrition, Learning and Behavior, pp. 269-277 (MIT Press, Cambridge, Massachusetts, 1968).

22. Naeye, R. L.: In: H. W. Waisman, and G. R. Kerr: Fetal Growth and Development, pp. 241-252 (McGraw-Hill, New York, 1970).

23. Nelson, K. B., and Deutschberger, J.: Develop. Med. Child Neurol., 12: 487 (1970).

24. Sindram, I. S.: Ned. T. Verlosk., 45: (1945).

25. Smith, C. A.: Amer. J. Obstet. Gynecol., 3: 599 (1947).

26. Solth, K.: Zbl. Gynak., 83: 1558 (1961).

27. Stein, Z., and Kassab, H.: In: J. Wortis: Mental Retardation pp. 92-116 (Grune and Stratton, Inc., New York, 1970).

28. Stein, Z., Susser, M., Saenger, G., and Marolla, F.: Science, 178: 708 (1972).

29. Stein, Z., Susser, M., Saenger, G., and Marolla, F.: Famine and Human Development: The Dutch Hunger Winter of 1944/45. (Oxford University Press, New York, 1975).

30. Stoch, M. B., and Smythe, P. M.: Arch. Dis. Childhood, 38: 546 (1963).

31. Stroink, J.: Ned. T. Verlosk., 47: 101 (1947).

32. Thomson, A. M.: Brit. J. Nutr., 13: 509 (1959).

33. Thomson, A. M., and Billewicz, W. Z.: Brit. J. Nutr. 15: 241 (1961).

34. Thomson, A. M., and Billewicz, W. Z.: J. Obstet. Gynaecol. Brit. Commonw., 76: 865 (1969).

35. Winick, M.: J. Pediat. 71: 390 (1967).

36. Winick, M.: Amer. J. Obstet. Gynecol., 109: 166 (1971).

37. Winick, M., Coscia, A. and Noble, A.: Pediatrics, 39: 248 (1967).

38. The data are not presented by the sex of the infant. Analysis did not reveal notable differences between males and females in their susceptibility to famine effects; as expected males were larger than females, but their growth patterns were not more sensitive to nutritional deprivation.

39. Official rations were supplemented in unofficial ways; estimates of supplements are given in the SHAEF report of the famine (6). The full analysis on which this conclusion is based is lengthy and will appear elsewhere (29). A cruder check can be made by relating the dates of birth of cohorts to the information on nutrients in Table 1.

40. The levels of statistical significance of these results have been thoroughly examined. They are not reported here, since the procedures involved extensive additional analysis in which official food rations were converted into quantified variables for each trimester or gestation. Food deprivation in the third trimester had significant effects on all dependent variables excepting length of gestation. There was a balanced deprivation of nutrients and we could not discriminate between the effects of calories, proteins, fats, and carbohydrates.

41. We owe much to many willing helpers in the Netherlands and most especially to our Dutch Steering Committee: Professor J. Bastiaans, Chairman; Professor J. Godefroy, Vice-Chairman; Dr. M. J. V. de Groot, Professor C. Den Hartog, Col. J. M. Lagendijk, Professor H. H. van Gelderen, Professor J. J. Groen, Professor N. Speijer, and Mr. A. Straatsma. Dr. F. M. Sorel voluntarily undertook many additional tasks. Dr. J. J. Huisjes of Groningen, Professor A. Sikkel of Leiden University, Professor G. J, Kloosterman of Amsterdam University, Dr. R. J. J. Omer of the St. Elizabeth Clinic in Heerlen and Dr. R. van Wering of the Midwives' Hospital in Rotterdam willingly gave us access to data from their obstetric services. Dr. W. op den Velde, Ms. B. L. Huidekoper and Ms. H. v. d. Made were also instrumental in gathering obstetric data. Our colleagues Francis Marolla and 
Gerhart Saenger participated in the project from which this report derives. Thanks are due to Patricia Zybert for her work on the diagrams.

42. The study was carried out with the assistance of funds from the National Institute of Health (Grants nos. 3-R01-HD-04454 and 5-R01-HD-06751) and the New York State Department of
Mental Hygiene. The writing of this paper was greatly facilitated by the award of a John Simon Guggenheim Fellowship for $1972-1973$ to one of us Dr. M. Susser.

43. Requests for reprints should be addressed to: Z. Stein, M.A.,

M.D., B.Ch., $600 \mathrm{~W}, 168$ th St., New York, N.Y. 10032 (USA). 44. Accepted for publication September 6, 1974.

Pediat. Res. 9: 76-83 (1975)

Birth weight

famine

gestation

Printed in U.S.A.

\title{
The Dutch Famine, 1944-1945, and the Reproductive Process. II. Interrelations of Caloric Rations and Six Indices at Birth
}

growth nutrition placenta

\author{
New York State Department of Hygiene and Surgeons and School of Public Health, Columbia University, \\ New York, New York, USA
}

ZENA STEIN(12) AND MERVYN SUSSER

\begin{abstract}
$\checkmark$
\end{abstract}

\section{Extract}

Effects of maternal exposure to famine during the prenatal period were compared among six indices of reproduction by the use of $\mathrm{Z}$ scores. Maternal weight was affected soonest, then birthweight and placental weight. Length and head size at birth were affected relatively less and only after exposure to more severe nutritional deprivation. Path models were constructed of the interrelations of caloric rations, length of gestation, maternal weight, and fetal dimensions. Above a threshold value of $1,500 \mathrm{Cal}$ daily average official food rations available to mothers in the third trimester, a model in which the placenta is treated as a fetal dimension (or organ) seemed most appropriate. Below the threshold value, a model in which the placenta is treated as a transmitter of nutrients seemed most appropriate.

\section{Speculation}

With severe nutritional deprivation, a pregnant mother interposes a buffer that protects the fetus until her nutrient reserves are exhausted. Under normal conditions the growth of the placenta is determined by the growth of the fetus. Under conditions of severe nutritional deprivation, the needs of the placenta are supplied first, and the placenta may thus restrict fetal growth.

In this paper we aim to elicit a structure of relations among indices of the reproductive process measured at birth. To do this, we have taken advantage of data collected for a study of the effects of the Dutch famine of 1944-1945 on fetal growth. A description of the circumstances of the famine as well as the context of this study and its detailed results are to be published elsewhere (7).

The average diet of pregnant women at different stages of gestation was treated as the hypothetical causal variable under study. We quantified an average diet from the official food ration. There was no doubt about the logical priority of the diet in relation to the available indices of the reproductive process. The dimensions of the infant, placental weight, and the end point of gestation, however, were necessarily measured at the same time. With these dependent variables, therefore, no design could confer certainty either about their ordering in time or about the directions of change among them. To assist us in the difficult task of judging among many alternatives about time order and direction of change, we took successive steps in the analysis of the sequences among the outcomes of the reproductive process. First, we made a graphic representation to show the changes through time of all of the variables concurrently. These graphs suggested a number of conclusions.

We then turned to multiple regression analysis to test, elaborate, and add to these conclusions. By applying these analytic procedures first to a series of three-variable sets, and then to larger sets of variables, we gained a good sense of the relations among the variables and strengthened our grasp of the logical priorities (Tables 1-3). Our object was to arrive at a tenable model of the direction and strength of the paths between all of the variables for which we had measures. Path analysis was necessarily the last step, for it imposes on investigators the salutary discipline of making explicit at the outset the hypotheses underlying their conception of the relations between variables (7-9).

We first present the data in graphic form, then present the path models. The intervening steps of analysis and inference from which we derived the structure of the variables in our path models are detailed elsewhere (7).

\section{GRAPHIC PRESENTATION}

We first graphed the six variables of the reproductive process for three famine-stricken cities against caloric rations and 